\title{
Bacterial Surface Layer Proteins: From Moonlighting to Biomimetics: A New Horizonto Lead
}

\author{
Nimisha Gaur, Ankit Sharma, Barkha Singhal ${ }^{*}$ \\ School of Biotechnology Gautam Buddha University, Greater Noida (U.P.), India \\ Email: charunimisha11@gmail.com, ankit1995atlas@gmail.com, *barkha@gbu.ac.in, *gupta.barkha@gmail.com
}

How to cite this paper: Gaur, N., Sharma, A. and Singhal, B. (2018) Bacterial Surface Layer Proteins: From Moonlighting to Biomimetics: A New Horizonto Lead. $A d$ vances in Bioscience and Biotechnology, 9, 352-372.

https://doi.org/10.4236/abb.2018.98023

Received: June 19, 2018

Accepted: August 10, 2018

Published: August 13, 2018

Copyright $\odot 2018$ by authors and Scientific Research Publishing Inc. This work is licensed under the Creative Commons Attribution International License (CC BY 4.0).

http://creativecommons.org/licenses/by/4.0/

\begin{abstract}
The landmark discovery of moonlighting proteins embarks the significant progress in understanding the biological complexity and their closed-circuit analysis. The growing continuum in the variety of moonlighting functions paved the way for further elucidation of structural-functional aspects of protein evolution and design of proteins with novel functions. Currently, the moonlighting functions in various adhesive properties of surface layer proteins, an essential component of cell surface architecture of archaea and all phylogenetic groups of eubacteria become more prominently recognized. The remarkable credentials of surface layer proteins to self-assemble into supramolecular structures at nano-scale dimension have been exploited for the production of smart biomaterials in the form of biomimetics has been thrust area of research. The finely tuned topological features in terms of shape, size, geometry and surface chemistry of surface layer proteins are crucial for the production of biomimetics. The current developments of biomimetic lipid bilayers and composite membranes find applicability in understanding the functional dynamism of evolutionary relationship of bacterial cell envelopes and vaccine development, drug development and drug delivery. Though the development of biomimetics embraces fascination but faces with technological challenges. The plethora of literature has been available for the moonlighting aspects and nano-technological applications separately but none of the review describes towards the rhythmic transition from moonlighting functions of surface layer proteins of bacteria to biomimetics development and applications. Therefore, this review describes certain basic aspects of moonlighting functions and their mechanism of action, surface layer proteins and their moonlighting functions of commensal bacteria and their transition towards biomimetics. The recent developments of biomimetics based on surface layer proteins have been summarized and also posited different chal-
\end{abstract}


lenges and future prospects.

\section{Keywords}

Moonlighting, Biomimetic, Surface Layer Proteins, Self-Assembly, Nano-Biotechnology

\section{Introduction}

The remarkable coordination of the cellular activities is manifested by the synergistic interaction between the macromolecules that makes the cells as highly organized network. Currently, the simplicity of Beadle and Tatum hypothesis of one gene codes for one protein that attains single functionality [1] has been overruled by envisaging two or more different functions encoded by single polypeptide chain. This remarkable phenomenon of adding cellular complexity and providing beneficial effects to the cell has been termed as "Moonlighting" described by Wistow and Piatigorsky in the era of 1980s [2]. The property of moonlighting doesn't imply for the fusion of genes transcribed to the proteins having multifunctionality, variants of splicing phenomenon or fragmentation of proteins attaining different functions due to proteolysis reaction [3] [4]. Various research studies supported that majority of the proteins have been found to perform multiple functions in living systems including animals, plants, prokaryotes [5]. The vast diversity has been visualized in the types of moonlighting proteins that includes receptors, transcription factors, glycolytic and metabolic enzymes, scaffolds, molecular chaperones and adhesins [6]. Apart from the variation in types of moonlighting proteins, considerable diversity has been envisaged in cellular location (such as nucleus, cytoplasm, and plasma membrane) and cell types even species level for the expression of moonlighting proteins [7]. The number of moonlighting proteins has been continuously growing and the phenomenon is not considered as an oddity because the multifunctionality of moonlighting proteins are an orchestral program by which the complexity of cells has been appropriately justified [8].

Among the wide arena of biomolecules, proteins recognized as "the most versatile class of biomolecules", surface layer proteins are the preliminary site of interaction of the cell with the outer environment and represented themselves as omnifarious functionality in-terms of cellular interactivity, structural framework, signal reception and mediator for understanding the evolutionary relationship [9] [10]. The surface layer proteins of pathogenic bacteria also show virulent properties but moonlighting of surface layer proteins of non-pathogenic strains retains its fascination due to the appealing property of self-assembly on various surfaces as well as interfaces performing evolutionarily finely-tuned functions [11]. The scarcity of the biopolymers having the property of self-assembly in an organized manner leads to a great interest in the surface 
layer proteins for the supra-molecular engineering [12] [13]. These proteins serve as latest conduits for the integration of these proteins with non-living system for the creation of biomimetic platform for the potential applications in material science and biotechnology [14]. Though the concept of moonlighting proteins becomes arisen from gram positive virulent bacteria in which these proteins performed virulence associated functions. Therefore, initial studies were correlated with their importance in pathogenesis related factors but with the advent of technological interventions moonlighting proteins have also been identified in gram-negative and commensal bacteria [15] [16]. The comprehensive understanding of structural, genetic and biochemical factors of surface layer proteins paved the way from conceptual science to translational applications and represented as an excellent example of biology-chemistry interface that can be considered as "New Horizon to Lead" [10]. Till date, for the development of biomimetic platform, the bacterial surface layer proteins have been explicitly utilized [17]. Therefore, the present review focused on the current understanding of moonlighting functions of surface layer proteins in different non-pathogenic bacteria and their technological functions in development of biomimetics. The review also posits the current bottlenecks and future directions for this research.

\section{Conceptual Aspects of Surface Layer Proteins}

Surface-layer (S-layer) proteins are the most abundant bacterial proteins and represents the outermost covering of majority of eubacteria and all archaea with unit cell size (3 to $30 \mathrm{~nm}$ ) and thicknesses of approximately $10 \mathrm{~nm}$ [18]. Owing to their location at cell surface, these proteins perform multitasking in terms of imparting the structural framework, tool for understanding the mechanism of evolutionary relationship, as a vehicle for the effective transport and synthesis, protection from the infectious pathogens in commensal bacteria [19]. The pictorial representation of the location of surface layer proteins in Archaebacteria and Eubacteria are depicted in Figure 1. The analysis of high performance analytical methodologies revealed that the overall thickness of surface layer has been observed from 5 to $25 \mathrm{~nm}$ thick and represented themselves as smooth towards outer surface and corrugated towards inner surface while a pillar like protrusions are present towards the inner surface in archaeal S-layer lattice [20]. The crystalline nature of these proteins revealed different symmetrical patterns including oblique ( $\mathrm{p} 1, \mathrm{p} 2)$, hexagonal ( $\mathrm{p} 3, \mathrm{p}$ 6) or tetragonal ( $\mathrm{p} 4)$ that leads to different morphological units of surface layer proteins from monomeric to hexameric [21] [22]. The elucidation of biochemical properties demonstrated that these proteins are stable towards extreme $\mathrm{pH}$ environments, fluctuating temperature range, radiations, proteolytic enzymes, detergents and high pressure [23]. Therefore, it was concluded that surface layer proteins confer varied canonical role but significant protective role against hostile factors can be associated with moonlighting properties [24]. The magnificent properties of self-assembly 
(a)

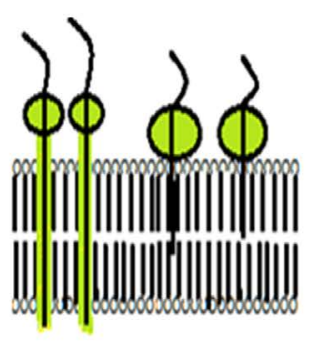

Bacteria (d) Gram positive

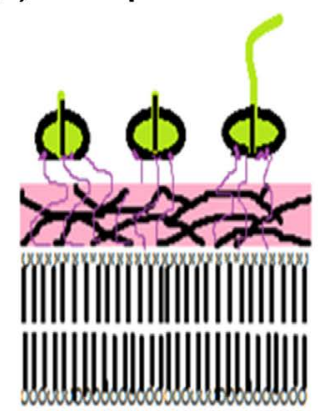

(c)

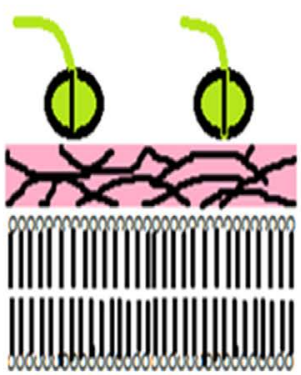

(e)

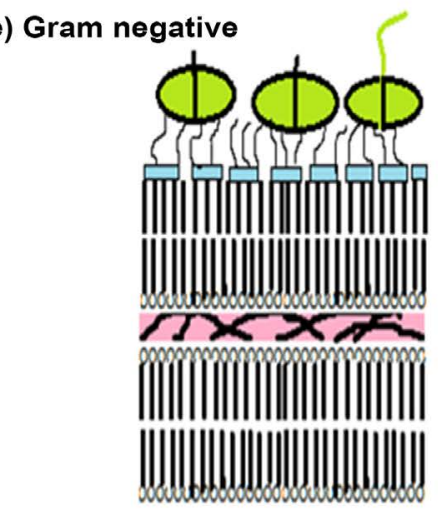

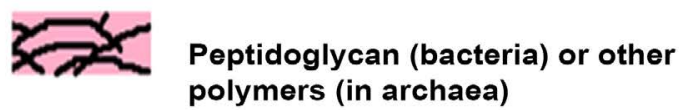

Membrane lipids

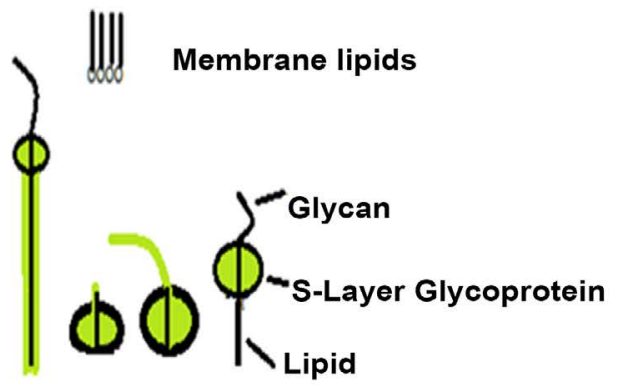

Secondry cell wall polymer

Lipo-polysaccharide

Figure 1. Representation of Surface layer proteins in the cell envelopes of Prokaryotes including Archaebacteria and Eubacteria [10] [19] [20] [21] (S-Layer in archaea have (glycol) protein lattices as a major cell component with mushroom-like subunits with pillar like, hydrophobic trans-membrane domains (a) with lipid modified glycoprotein subunits; (b) S-layer consisting glycoproteins having both types of membrane anchoring mechanisms; (c) Archaea having a rigid wall layer composed of Pseudomurein. In gram positive bacteria d) the S-layer glycoproteins are bound to the rigid peptidoglycan containing layer via secondary cell wall polymers (SCWP'S). In Gram-negative bacteria (e) the surface layer is closely associated with the lipopolysaccharide of the outer membrane).

of these proteins laid a foundation for designing of three-dimensional nanoscale systems for the engineering of biomaterials for further technological modifications [25].

\section{Mechanisms of Moonlighting Functions}

The intricate functioning of moonlighting proteins are quite varied in-terms of cellular location and type and oligomeric state of the protein, cellular concentration of a ligand, cofactor and substrate or other perturbations [26]. Research studies confirmed that the different parts of the same proteins or alternatively attaining the different confirmations or partially overlapping of some parts of proteins are responsible for their canonical and moonlighting functions. The moonlighting functions are achieved by using different combination of the above described methods [25] [27] and represented in Figure 2. The overall impact of moonlighting functions can be envisaged in different level of living organization i.e. from molecular level to organismal. The different hierarchal level of mechanism of moonlighting functions is depicted in Figure 3. With 


\section{(a) Oilgomerization}

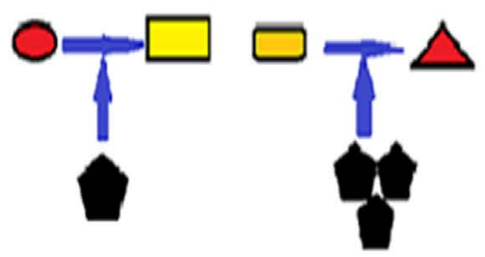

(d) Different locations within the cell

(b) Expression by different cell types
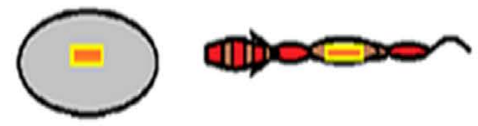

e) Ligand/substrate concentration (c) Inside and outside the cell

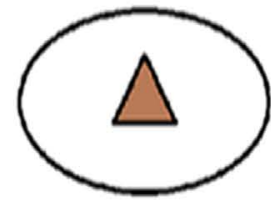

$\triangle$
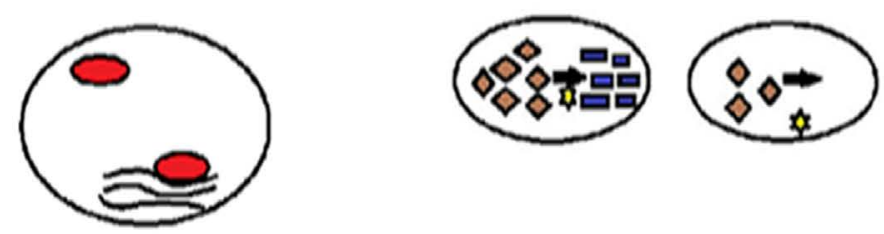

(f) Multiple binding sites

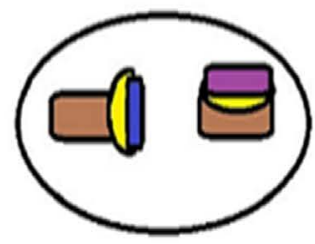

Figure 2. Mechanism of moonlighting function of proteins [7].

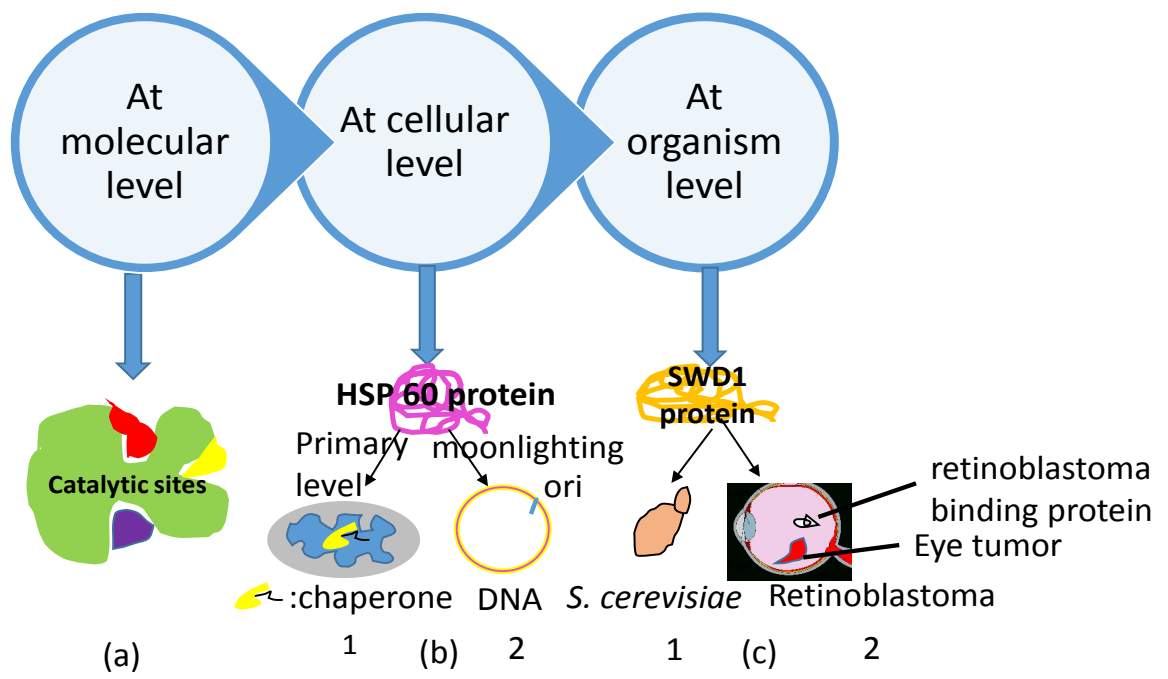

Figure 3. Different levels of functionality of Moonlighting functions of proteins [2] [28]. (a) Multifunctionality due to multiple catalytic domains of HSP 60 protein in S. cerevisiae; (b) Gene products at multiple biological processes at 1 . Primary level as mitochondrial chaperone 2. moonlighting as stabilization of DNA ori's; (c) Pleiotropy for example SWD1 protein found in 1 . S. cerevisiae is similar to 2 . human retinoblastoma binding protein.

examples. The molecular level defines the possession of multiple varied catalytic domains in the same proteins. The cellular level the multifunctionality has been assessed in terms of gene products responsible for regulating the variety of biological process while at organismal level the moonlighting can be visualized by multiple phenotypic effects or pleiotropy [2] [28].

\section{Types of Moonlighting Proteins}

There has been continuous fascination towards the studies of moonlighting pro- 
teins due to the growing continuum of number of these proteins. The wide arena of biological molecules serves the moonlighting functions. These diversified molecules include receptors, metabolic enzymes, chaperones, ribosomal proteins and transmembrane channels [29] [30]. The thorough understanding of these proteins elucidates their more functional aspects at genomics and proteomics level [31].

\section{Moonlighting Functions of Surface Layer Proteins}

The past decade has seen the tremendous increments in the number and functions of moonlighting proteins among the diversified group of bacteria. Though the research on bacterial moonlighting proteins has been more stressed towards virulence-associated functions but lots of moonlighting proteins have been determined on cell-surface-associated and/or in extracellular space of commensal bacteria as well [32]. Apart from the canonical function of surface layer proteins, adhesive moonlighting functions have been recognized now-a-days. The adhesive moonlighting functions of surface layer proteins include binding with extracellular matrices, lymphocytes, epithelial cells, secreted mucins, effector molecules, monocytes and other living cells. The research studies reported that the binding of $L$. plantarum efficiently adheres to colon by binding with mucin due to moonlighting functions of GAPDH [33]. While this enzyme also shown to bind antigenic molecules of $\mathrm{A}$ and $\mathrm{B}$ blood group present in the intestinal mucin as well as fibronectin [34]. In addition to that, the cell surface of L. johnsonii Lal (NCC533) contain elongation factor (EF-Tu) that binds with mucin and human intestinal epithelial cells [35]. This binding was highly efficient at $\mathrm{pH}$ 5 than at $\mathrm{pH} 7.2$ [36]. Moreover, the research studies also confirmed the presence of GroEL on the cell surface of $L$. johnsonii Lal and binds with extracellular matrix proteins [37]. In fact, the aggregation of prominent gastric pathogen $\mathrm{He}$ licobacter pylori was induced by interleukin- 8 that has been stimulated by recombinant GroEL [38]. Furthermore, the adhesiveness of Neisseria gonorrhoeae to epithelial cells has been inhibited by the presence of cell surface enolase of a vaginal commensal bacterium, L. jensenii [39]. Moreover, enolase and GAPDH present in the extracellular proteome of $L$. crispatus $S T 1$ and other commensal species has been shown to enhance tPA-mediated plasminogen activation [40]. In continuation of this the binding of Bifidobacterium animalissubsplactis [41] with host has also been associated with plasminogen binding [42]. This bacterial cell recruit's plasminogen to the cell surface, that is further converted to plasmin by the activators present in the host [43]. This plasmin has also been responsible for degrading various extracellular matrix components, fibronectin and fibrinogen that mediates the colonization of the host [44]. Research studies identified this putative plasminogen binding proteins that includes phosphoglycerate mutase, enolase, bile salt hydrolase, GS, DnaK, in B. animalis subsp. lactis. [45]. Apart from that enolase was also identified as surface-localized plasminogen binding protein in other Bifido species like Bifidobacterium bifidum, Bifidobac- 
terium breve, Bifidobacterium longum [46]. Apart from that the binding of laminin and collagen I was also mediated by the enolase present in the cell surface of Lactobacillus crispatus but showed no association fibronectin and collagen IV [47]. In addition to that other moonlighting proteins were also identified like glucose-6-phosphate isomerase (GPI), phosphoglycerate kinase, triose phosphate isomerase that mediated adhesion of several Lactobacillus species with their host cells [48]. Furthermore, the immunomodulatory activity of heat shock protein GroEL has been visualized to stimulate IL-8 release by HT-29 cells in the presence of soluble CD 14 from different Gram-positive bacteria including $L$. johnsonii, Lactococcuslactis and Bacillus subtilis [39].

\section{Need of Biomimetics}

The faster pace of industrialization paved the way for increasing pollution as well as environment degradation at an alarming rate. However, the limited natural resources always lead to the dilemmatic situation for the survival and improvement in the quality of the life of mankind. The ultimate solution of this situation always lies in nature and now-a-days the scientific community find the interesting way for solving this problem through nature inspired field designated as Biomimetics [49] [50]. The need of biomimetics is depicted in Figure 4. The terminology came from Greek words "bios" (life) and "mimesis" (to imitate or copy) leads to "biomimetics" the creative technology that mimics the functionality of nature [51]. The technology has not originated recently, the concept and utilization of bio-inspired material has been utilized since prolonged time by using different nomenclature in different countries like "smart material" in the USA and "intellectual structure" in Japan [52]. The time-line diagram (Figure 5) shows the various developments in the field of biomimetics [53] [54]. Though all biological entities are entitled to the bioengineering for the creation of biomimetics by molecular level manipulation but surface layer proteins have attracted a widespread attention by possessing magnificent credentials in terms of selectivity, imparting elasticity, provokes cross-linking, promoting biomineralization, possessing highly specific binding, facilitating material degradation and more emphatically molecular self-assembly [51] [55]. The amalgamation of interdisciplinary fields like nanobiotechnology, molecular nanotechnology and supramolecular engineering of biological systems leads to paradigmatic shift in the field of biomimetics [56] [57].

\section{Concept of Biomimetics Based on Surface Layer Proteins}

The outermost envelope possessing oriented self-assembly of proteins are not restricted only to prokaryotic bacterial species but also found in archaea and virus [22]. The comprehensive literature has been documented on the biochemical aspects, self-assembling properties and genetic framework of surface layer proteins but their technical utilization is under the stage of infancy till date [18]. Currently, S-layer proteins from Gram-positive bacteria has been explicitly 


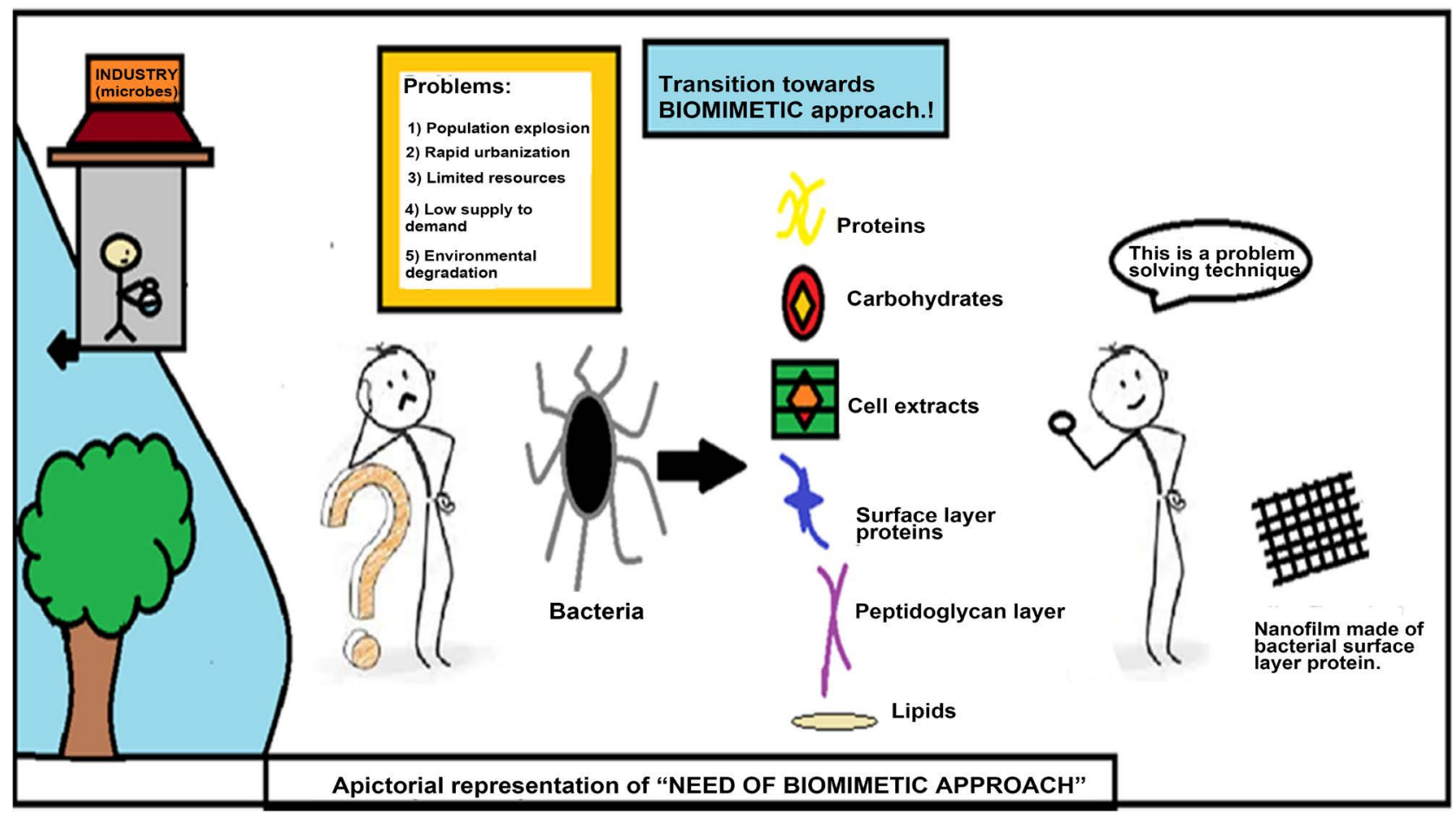

Figure 4. Need of biomimetic approach.

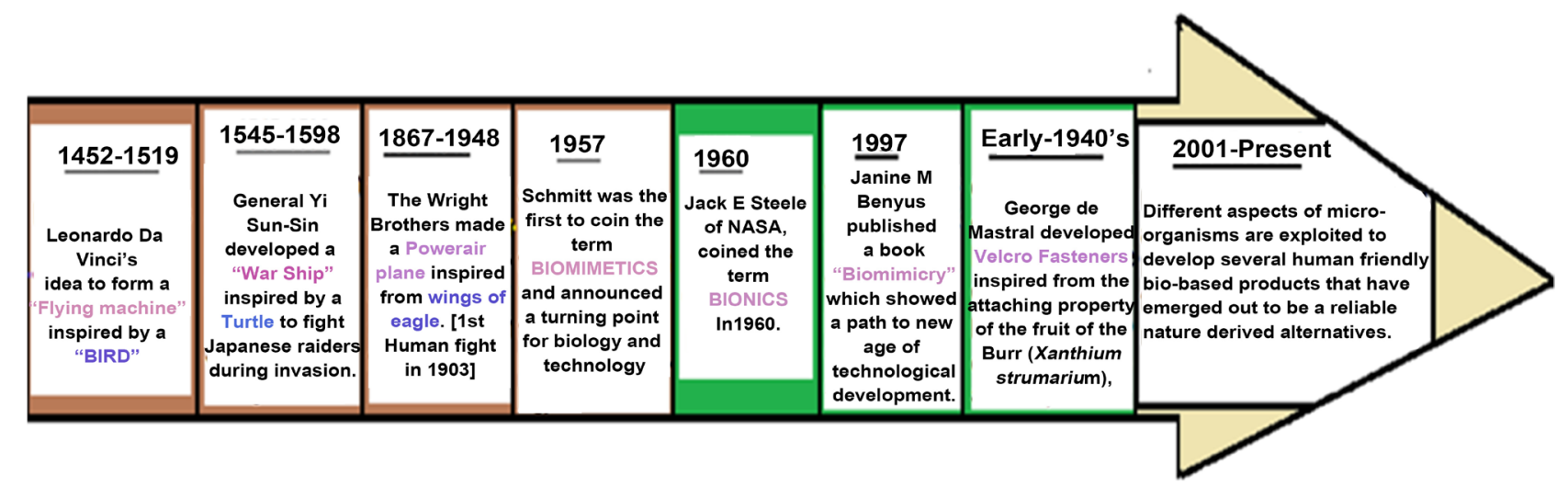

Figure 5. Time-Line diagram showing development of Biomimetic.

utilized for the supramolecular organization for the development of biomimetic platforms. The utilization of S-layer protein of Lysinibacillus sphaericus CCM 2177 (SbpA) for the construction of biomimetic platform has been explored due to its remarkable antifouling characteristic in the presence of plasma, blood and high concentration of other protein solutions. Similarly, biomimetic membranes were also constructed from S-layer protein SbsB from Geobacillus stearothermophilus PV72/p2 [21]. Currently, the versatility in terms of biomimetics has been envisaged in the generation of biomimetic membranes, liposomes, emulsomes and composite biomimetic membranes that have tremendous multiple application in health, medicine, environment etc. [58]. The details of the surface layer proteins based biomimetic are described below. 


\subsection{Surface Layer Proteins Based Biomimmetic Membranes}

The past decade has seen tremendous progress in the development of biological membranes as twenty percent of the genome of an organism constituting the genes for membrane proteins like ion channels, transmembrane receptors, surface receptors, porins and membrane bound enzymes [59]. These molecules play vital role in the metabolic activities and serves as preferred targets for therapeutic interventions [60]. Therefore, the generation of membranes mimicking the biological functionality in-terms of functional membrane proteins accelerates the development of novel drugs, biosensing platforms and protein-ligand screening [61]. The most promising approach applied till date the generation of S-layer stabilized lipid membranes. In this biomimetic construction, synthetic lipids (either phospholipids or tetraether) replace the cytoplasmic membrane and S-layer proteins are attached either on one or both sides of the lipid membrane representing excellent bio-functional surfaces and stabilizing functionalized lipid membranes [62]. Furthermore, the longevity of these stabilized membranes has been strengthening by recrystallization of these proteins on the top of the previously generated SsLM [63]. These membranes mimic the supramolecular assembling principle of archaeal envelopes as archaea are composed of cytoplasmic membrane and a closely associated S-layer as exclusive wall component [64]. These composite structures have advantage of mimicking their natural counterpart in-terms of sustainability over extreme environmental parameters, stabilization over mechanical and osmotic stress [65]. The various biochemical mechanism has been seen for the interaction of phospholipids with various domains or amino acid residues of the surface layer proteins. These includes either modification of the S-layer protein residues chemically or utilizing cross linker molecules for the indirect coupling of the S-layer protein or construction of fusion surface layer proteins by genetic engineering for the subsequent binding with lipid moieties [66]. On the basis of these non-covalent interaction of S-layer proteins with lipid head groups broadly two types of biomimetic membranes have been developed i.e. planar and spherical lipid mono- and bilayers [67].

\subsubsection{Planar Biomimetic Membranes}

These membranes serve as magnificent biomimetic model to comprehend the surface characteristics of archaeal cell surface as well as found significant applications in material science and provide amphiphilic matrix for the constitution of membrane proteins [68]. The considerable variety has been visualized for the construction of these membranes and these are classified as freestanding bilayer lipid membrane (BLM) and folded bilayer lipid membrane [69]. In the first step, monolayers have been formed by dissolving phospholipids in variety of non-polar volatile solvents such as hexane, chloroform, pentane followed by evaporation of these solvents for the formation at the air-solution interface [70]. Free standing bilayer biomimetic set up was made through an aperture followed by linking of two fluid filled compartments in which either individual or mixture of phospholipid solutions are immersed in non-polar solvents [71]. The aperture 
on which the bilayer has been formed it has to "primed" with phospholipid mixture followed by drying in air [72]. On the other hand, "folded" bilayers biomimetic interface has been formed at air-water interface through the opposition of two phospholipid monolayers [73]. This type of biomimetic surface requires less solvent as compared with freestanding lipid bilayers. By generating such type of membrane interface, dip-tip technology has been applied for their practical implementation, the polar head groups of the phospholipids orientate faces with the aqueous solution while hydrocarbon chains of the molecules face in that air followed by subsequent recrystallization of an S-layer protein. The coating with surface layer proteins alter the capacitance and resistance of lipid bilayer as well as conferring the capacity of tolerating the high pressure that leads to higher osmo-protective properties of these membranes. Though the remarkable mechanical strength has been imparted by the above described lipid bilayers membranes after the coating of surface layer proteins, but their stability has not been seen that can be extended for more practical applications. Therefore, various solid organic and inorganic supports have been tried to enhance their mechanical stability. The principle of Langmuir-Blodgett/Langmuir-Schaefer technique has been implied for the recrystallization of S-layer proteins on glass and modified silicon surfaces before generating a tetraether either lipid monolayer or bilayer. The different geometrical pattern of solid supported biomimetic membranes is depicted in Figure 6.

\subsubsection{Spherical Lipid Biomimetic Membranes}

The charge and geometry of lipids directly influencing their self-assembly either into bilayers or vesicles [74]. The spherical bilayers are more promisingly known as vesicles having the range of $50 \mathrm{~nm}-1 \mu \mathrm{m}$. the vesicles composed of mono spherical bilayers are known as uni-lamellar vesicles while vesicles composed of multi-lipid bilayers are known as multi-lamellar vesicles or liposomes [75].

\section{1) Liposomes}

Liposomes have inner aqueous environment and outer hydrophobic moieties that rendered them as an excellent carrier for drug delivery [76]. It has been seen that covering of outermost envelope structure of multi-lamellar vesicles with surface layer proteins enabled the well-defined orientation, spatial distribution of target molecules resembling the "artificial cell envelopes" or "artificial virus-like particles" [77]. Currently, the research studies giving convincing evidence for the promotion of protein-liposome interactions [78]. S-layer proteins from various probiotic Lactobacillus species has been utilized for stabilization of positively charged liposomes by decreasing liposome fusion by promoting the stearic hindrance for surface interaction through inclusion of bulky chains and moieties protruding from the lipid bilayer membrane [79]. Furthermore, in the presence of surface layer proteins there is the charge neutralization occurs at membrane interface followed by the enhancement of bilayer packing and permeability [80]. For example, the S-layer proteins of Lactobacillus brevis and Lactobacillus kefir has been utilized for development of liposomes as vaccines 


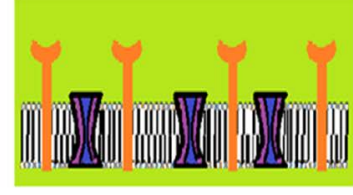

(a)

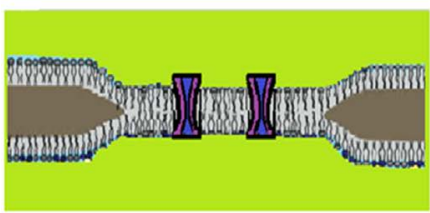

(d)

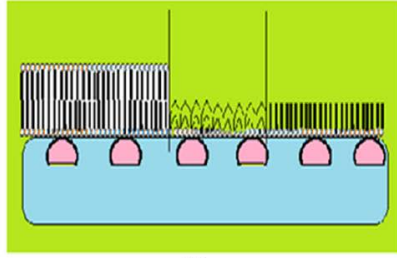

(b)

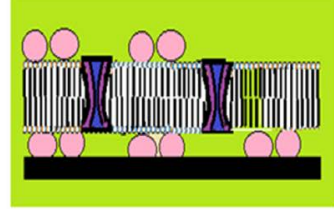

(e)

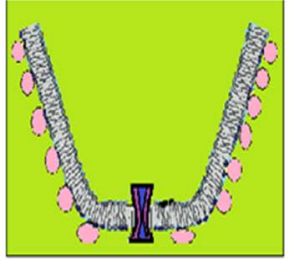

(c)

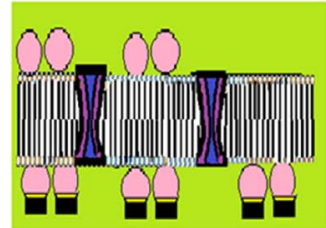

(f)

Figure 6. Representation of various Biomimetic membranes based on surface layer proteins [9] [21] [69]. (a) S-Layer supported lipid bilayers; (b) Lipid monolayer films at the air/water interphase with an underneath recrystallized S-Layer lattice; (c) Tetraether lipid monolayer in the upright conformation; (d) Tetraether lipid monolayer in the U-shaped (bent) conformation. 3.) Phospholipid monolayer; (e) A tetraether lipid monolayer membrane is generated across an orifice of a patch-clamp pipette by the tip-dip method. Subsequently a closely attached S-layer is formed by bacterial S-layer proteins on one side of the lipid membrane. In ( $\mathrm{f}$ ) a folded or painted bilayer phospholipid membrane spanning a Teflon aperture is shown. A closed bacterial S-layer lattice can be self -assembled on either one or both (not shown) sides of the lipid membrane.

for oral delivery [81]. In fact, the surface layer proteins from GRAS organism preferably from Lactobacillus species have remarkable credentials for coating with liposomes for vaccine development and drug delivery owing to their adhesive and immunomodulatory properties [82]. In addition to that, S-layer-coated liposomes provide a good platform for attachment of macromolecules like ferritin through covalent interactions [83]. The binding efficiency can also be enhanced by the biotinylation of S-layer-coated liposomes for binding with avidin [84]. This concept was utilized for the biotinylated antihuman immunoglobulin G (IgG) was attached through streptavidin to the biotinylated S-layer-coated liposomes [85]. Moreover, the advent of S-layer recombinant proteins has been conjugated with streptavidin with more precision and topographical orientation as well as constituting the sequence of the enhanced green fluorescent protein (EGFP) on liposomes [86].

\section{2) Emulsomes}

The past decade has seen tremendous advancements in the field of drug delivery vehicles. Though liposomes serve as potential vehicles for this purpose [87], but the lipophilic drugs cannot be effectively taken by the cells therefore a lipoidal vesicular system commonly known as emulsomes are the thrust area of research now-a-days [88]. The central core is composed of lipids that is surrounded by phospholipid multilayers [89]. The lipoidic core exists in solid or liquid crystalline phase rather than oily fluid phase [90]. The diagrammatic view of combined liposome and emulsomes are depicted in Figure 7. Therefore, this 


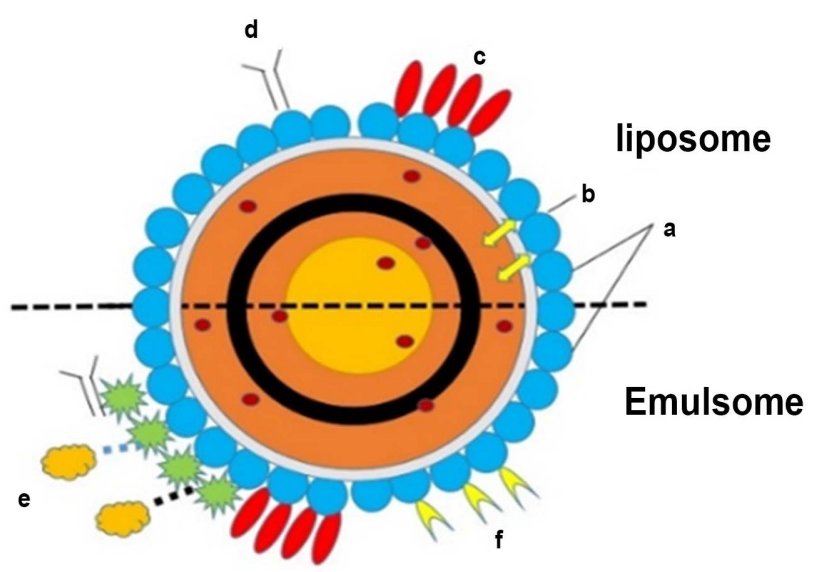

Figure 7. S layer coated emulsome and liposome [87] [88] (a) entrapped functional molecules, (b) integral proteins (c) ligands bounded to the S layer coated liposome or emulsome (d) immobilization via ligand protein $(\mathrm{e})$, ( $\mathrm{f}$ ) genetically modified S layer subunits.

serves as the basis of differentiating feature between emulsomes from emulsions and enabling the encapsulation of lipophilic compounds in higher amounts [91]. Therefore, it has several advantages for the betterment of drugs absorption including the enhancement of membrane permeability, bioavailability, inhibition of efflux transport, modulated enterocyte-based drug transport and targeted lymphatic system transport [92]. The utilization of recombinant surface layer proteins in the emulsomes also includes the diverse functional domains that may have potential applications in nanobiotechnology [64]. The literature possessing their translational applicability has been supported by various research studies. Recently, non-cytotoxic effect of S-layer-coated emulsomes has been reported in invitro cell culture studies in human liver carcinoma cells (HepG2) [77]. Furthermore, the enhancement of bioavailability of curcumin has been reported by the development of curcuemulsomes into HepG2 cells [93]. Moreover, renal toxicity has been reduced by the delivery of emulsome coated amphotericin B that has been used for the treatment of invasive fungal infections [94]. In addition to that trilaurin and tristearin based emulsomal formulations has been used for the targeted delivery of azidothymidine (AZT) and ensure the internalization of the encapsulated drug for the treatment of intracellular liver infections [95]. Moreover, the lymphatic delivery of methotrexate (MTX) in emulsome formulations has enhanced its bioavailability in treatment of cancer [96]. Now-days emulsomes coated with fusion proteins can also be used for the imaging purposes by enhanced Green fluorescent protein (EFGP).

\subsubsection{Composite Biomimetic Membranes}

The development of biomimetic membrane serves as an excellent model for studying the membrane structural and functional relationship. The main hurdle lies on the incorporation of membrane bound peptides as well as maintaining 
their functionality. Till date the research studies reported the specific and very few examples of these composite biomimetic surface that maintain the integrity by preserving their intricate functionality. The examples include the pore forming gramicidin as well as $\alpha$-haemolysin (aHL) as anti-microbial peptide [97], valinomycin as an ion carrier [98], peptidylglycylleucine-carboxyamide as AMP analogue [99], alamethicin as a channel-forming peptide [100], ion conducting channel of M2 segment in nicotinic acetylcholine receptor (nAChR) [101], voltage dependent anion channel (VDAC) and ryanodine receptor/Ca2p release channel (RyR1) [102]. The construction of biomimetic membranous network comprising these membrane active peptides has been performed in planar and spherical lipid bilayers has successfully been performed.

\section{Current Bottlenecks and Future Prospects}

The paradigmatic shift in the studies of surface layer proteins from basic functionality to moonlighting and further for the development of biomimetic platforms through supramolecular engineering represented an excellent example of translational application of biology-chemistry interface. Though the development of biomimetic entities incorporating surface layer proteins depicted a stable, sustainable approach, but still faces lots of technological challenges. The major challenge is associated with the compatibility, viability, stability and solubility of biological network with non-living system. The dynamic interactions among biological components as well as their scale up for their commercial utilization also poses great technological challenge. The glycosylation of majority of surface layer proteins has not been studied yet which may also restrict their applicability.

Though the above described challenges pose serious limitations for commercial utilization but it cannot stop for futuristic research and applicability. The prospective areas of future developments can be envisaged in high-throughput screening of various drug molecules, liposomes and emulsomes for vaccines and drug delivery, DNA sequencing, biosensors for the development of electronic noses and tongues, lab-on-chip devices.

\section{Conclusion}

In recent years, the continuing interest in moonlighting proteins has been highlighted due to the growing biological curiosity and complexity in all living systems. These specialized proteins are involved in various physiological and biochemical methods and expressed throughout the evolutionary tree. Simultaneously the growing population at global level and very limited choice of biological polymers to self-assemble, surface layer proteins depicted a promising platform for designing of supramolecular complexes for the development of biomimetic platforms. The development of different biomimetic lipid bilayer membranes adds dynamism for the thorough understanding of structural and functional relationship of archaeal and eukaryotic bacterial membrane counterparts 
as well as embraces with varied application in drug delivery, biosensing, biomineralization and nanobiotechnology. In spite of these remarkable developments, biomimetic applications of surface layer proteins represent only a fraction of potential applications inspired with natural resources and still need more exhaustive exploration for their wider utilization.

\section{Acknowledgements}

The technical support provided by the Gautam Buddha University is gratefully acknowledged.

\section{Conflicts of Interest}

The authors declare no conflicts of interest regarding the publication of this paper.

\section{References}

[1] Beadle, G.W. and Tatum, E.L. (1941) Genetic Control of Biochemical Reactions in Neurospora. Proceedings of the National Academy of Sciences, 27, 499-506. https://doi.org/10.1073/pnas.27.11.499

[2] Piatigorsky, J. and Wistow, G.J. (1989) Enzyme/Crystallins: Gene Sharing as an Evolutionary Strategy. Cell, 57, 197-199. https://doi.org/10.1016/0092-8674(89)90956-2

[3] Copley, S.D. (2012) Moonlighting Is Mainstream: Paradigm Adjustment Required. Bioessays, 34, 578-588. https://doi.org/10.1002/bies.201100191

[4] Henderson, B. and Martin, A.C.R. (2014) Protein Moonlighting: A New Factor in Biology and Medicine. Biochemical Society Transactions, 42, 1671-1678. https://doi.org/10.1042/BST20140273

[5] Bielli, P. and Calabrese, L. (2002) Structure to Function Relationships in Ceruloplasmin: A Moonlighting Protein. Cellular and Molecular Life Sciences CMLS, 59, 1413-1427. https://doi.org/10.1007/s00018-002-8519-2

[6] Jeffery, C.J. (1999) Moonlighting Proteins. Trends in Biochemical Sciences, 24, 8-11. https://doi.org/10.1016/S0968-0004(98)01335-8

[7] Huberts, D.H.E.W. and van der Klei, I.J. (2010) Moonlighting Proteins: An Intriguing Mode of Multitasking. Biochimica et Biophysica Acta (BBA)-Molecular Cell Research, 1803, 520-525. https://doi.org/10.1016/j.bbamcr.2010.01.022

[8] Jeffery, C.J. (2003) Moonlighting Proteins: Old Proteins Learning New Tricks. TRENDS in Genetics, 19, 415-417. https://doi.org/10.1016/S0168-9525(03)00167-7

[9] Sleytr, U.B., Messner, P., Pum, D. and Sára, M. (1999) Crystalline Bacterial Cell Surface Layers (S Layers): From Supramolecular Cell Structure to Biomimetics and Nanotechnology. Angewandte Chemie International Edition, 38, 1034-1054. https://doi.org/10.1002/(SICI)1521-3773(19990419)38:8<1034::AID-ANIE1034>3.0. CO;2-\#

[10] Sára, M. and Sleytr, U.B. (2000) S-Layer Proteins. Journal of Bacteriology, 182, 859-868. https://doi.org/10.1128/JB.182.4.859-868.2000

[11] Wang, G.Q., Xia, Y., Cui, J., Gu, Z.N., Song, Y.D., Chen, Y.Q., Chen, H.Q., Zhang, H. and Chen, W. (2013) The Roles of Moonlighting Proteins in Bacteria. Current Issues in Molecular Biology, 16, 15-22. 
[12] Guan, Z.B. (2007) Supramolecular Design in Biopolymers and Biomimetic Polymers for Advanced Mechanical Properties. Polymer International, 56, 467-473. https://doi.org/10.1002/pi.2245

[13] Karger-Kocsis, J. (2014) Biodegradable Polyester-Based Shape Memory Polymers: Concepts of (supra) Molecular Architecturing. Express Polymer Letters, 8, 397-412. https://doi.org/10.3144/expresspolymlett.2014.44

[14] Di Natale, C., Martinelli, E., Paolesse, R., Amico, A., Filippini, D. and Lundström, I. (2008) An Experimental Biomimetic Platform for Artificial Olfaction. PLoS One, 3, e3139. https://doi.org/10.1371/journal.pone.0003139

[15] Justyna, K.-K. and Kozik, A. (2014) Moonlighting Proteins as Virulence Factors of Pathogenic Fungi, Parasitic Protozoa and Multicellular Parasites. Molecular Oral Microbiology, 29, 270-283. https://doi.org/10.1111/omi.12078

[16] Henderson, B. and Martin, A. (2011) Bacterial Virulence in the Moonlight: Multitasking Bacterial Moonlighting Proteins Are Virulence Determinants in Infectious Disease. Infection and Immunity, 79, 3476-3491. https://doi.org/10.1128/IAI.00179-11

[17] Pavkov-Keller, T., Howorka, S. and Keller, W. (2011) The Structure of Bacterial S-Layer Proteins. Progress in Molecular Biology and Translational Science, 103, 73-130. https://doi.org/10.1016/B978-0-12-415906-8.00004-2

[18] Ilk, N., Egelseer, E.M. and Sleytr, U.B. (2011) S-Layer Fusion Proteins-Construction Principles and Applications. Current Opinion in Biotechnology, 22, 824-831. https://doi.org/10.1016/j.copbio.2011.05.510

[19] Fagan, R.P. and Fairweather, N.F. (2014) Biogenesis and Functions of Bacterial S-Layers. Nature Reviews Microbiology, 12, 211-222. https://doi.org/10.1038/nrmicro3213

[20] Schuster, B. and Sleytr, U.B. (2014) Biomimetic Interfaces Based on S-Layer Proteins, Lipid Membranes and Functional Biomolecules. Journal of the Royal Society Interface, 11, Article ID: 20140232. https://doi.org/10.1098/rsif.2014.0232

[21] Arbing, M.A., Chan, S., Shin, A., Phan, T., Ahn, C.J., Rohlin, L. and Gunsalus, R.P. (2012) Structure of the Surface Layer of the Methanogenic Archaea Methanosarcina acetivorans. Proceedings of the National Academy of Sciences, 109, 11812-11817. https://doi.org/10.1073/pnas.1120595109

[22] Rothbauer, M., Küpcu, S., Sticker, D., Sleytr, U.B. and Ertl, P. (2013) Exploitation of S-Layer Anisotropy: pH-Dependent Nanolayer Orientation for Cellular Micropatterning. ACS Nano, 7, 8020-8030. https://doi.org/10.1021/nn403198a

[23] Sengupta, S., Ghosh, S. and Nagaraja, V. (2008) Moonlighting Function of Glutamate Racemase from Mycobacterium tuberculosis: Racemization and DNA Gyrase Inhibition Are Two Independent Activities of the Enzyme. Microbiology, 154, 2796-2803. https://doi.org/10.1099/mic.0.2008/020933-0

[24] Pum, D. and Sleytr, U.B. (2014) Reassembly of S-Layer Proteins. Nanotechnology, 25, Article ID: 312001. https://doi.org/10.1088/0957-4484/25/31/312001

[25] Sriram, G., Martinez, J.A., McCabe, E.R., Liao, J.C. and Dipple, K.M. (2005) Single-Gene Disorders: What Role Could Moonlighting Enzymes Play? The American Journal of Human Genetics, 76, 911-924. https://doi.org/10.1086/430799

[26] Gancedo, C. and Carmen-Lisset, F. (2008) Moonlighting Proteins in Yeasts. Microbiology and Molecular Biology Reviews, 72, 197-210. https://doi.org/10.1128/MMBR.00036-07

[27] Piatigorsky, J. (2007) Gene Sharing and Evolution: The Diversity of Protein Func- 
tions. Harvard University Press, Cambridge, 471-505. https://doi.org/10.4159/9780674042124

[28] Copley, S.D. (2003) Enzymes with Extra Talents: Moonlighting Functions and Catalytic Promiscuity. Current Opinion in Chemical Biology, 7, 265-272.

https://doi.org/10.1016/S1367-5931(03)00032-2

[29] Fares, M.A. (2014) The Evolution of Protein Moonlighting: Adaptive Traps and Promiscuity in the Chaperonins. Biochemical Society Transactions, 42, 1709-1714. https://doi.org/10.1042/BST20140225

[30] Todd, A.E., Orengo, C.A. and Thornton, J.M. (1999) Evolution of Protein Function, from a Structural Perspective. Current Opinion in Chemical Biology, 3, 548-556. https://doi.org/10.1016/S1367-5931(99)00007-1

[31] Kainulainen, V. and Korhonen, T.K. (2014) Dancing to Another Tune-Adhesive Moonlighting Proteins in Bacteria. Biology, 3, 178-204. https://doi.org/10.3390/biology3010178

[32] Górska, S., Buda, B., Brzozowska, E., Schwarzer, M., Srutkova, D., Kozakova, H. and Gamian, A. (2016) Identification of Lactobacillus Proteins with Different Recognition Patterns between Immune Rabbit Sera and Nonimmune Mice or Human Sera. BMC Microbiology, 16, 17. https://doi.org/10.1186/s12866-016-0631-9

[33] Sheokand, N., Malhotra, H., Kumar, S., Tillu, V.A., Chauhan, A.S., Raje, C.I. and Raje, M. (2014) Moonlighting Cell-Surface GAPDH Recruits Apotransferrin to Effect Iron Egress from Mammalian Cells. Journal of Cell Science, 127, 4279-4291. https://doi.org/10.1242/jcs.154005

[34] Granato, D., Bergonzelli, G.E., Pridmore, R.D., Marvin, L., Rouvet, M. and Corthésy-Theulaz, I.E. (2004) Cell Surface-Associated Elongation Factor Tu Mediates the Attachment of Lactobacillus johnsonii NCC533 (La1) to Human Intestinal Cells and Mucins. Infection and Immunity, 72, 2160-2169. https://doi.org/10.1128/IAI.72.4.2160-2169.2004

[35] Bergonzelli, G.E., Granato, D., Pridmore, R.D., Marvin-Guy, L.F., Donnicola, D. and Corthésy-Theulaz, I.E. (2006) GroEL of Lactobacillus johnsonii La1 (NCC 533) Is Cell Surface Associated: Potential Role in Interactions with the Host and the Gastric Pathogen Helicobacter pylori. Infection and Immunity, 74, 425-434. https://doi.org/10.1128/IAI.74.1.425-434.2006

[36] Beck, H.C., Madsen, S.M., Glenting, J., Petersen, J., Israelsen, H., Nørrelykke, M., Antonsson, M. and Hansen, A.M. (2009) Proteomic Analysis of Cell Surface-Associated Proteins from Probiotic Lactobacillus plantarum. FEMS Microbiology Letters, 297, 61-66. https://doi.org/10.1111/j.1574-6968.2009.01662.x

[37] Pachathundikandi, S.K., Lind, J., Tegtmeyer, N., El-Omar, E.M. and Backert, S. (2015) Interplay of the Gastric Pathogen Helicobacter pylori with Toll-Like Receptors. BioMed Research International, 2015, Article ID: 192420.

https://doi.org/10.1155/2015/192420

[38] Saroj, S.D., Maudsdotter, L., Tavares, R. and Jonsson, A.B. (2016) Lactobacilli Interfere with Streptococcus pyogenes Hemolytic Activity and Adherence to Host Epithelial Cells. Frontiers in Microbiology, 7, 1176.

https://doi.org/10.3389/fmicb.2016.01176

[39] Kainulainen, V. (2012) Moonlighting Proteins of Lactobacillus crispatus. Extracellular Localization, Cell Wall Anchoring and Interactions with the Host. DissertationesBiocentriViikkiUniversitatisHelsingiensis. http://hdl.handle.net/10138/28809

[40] Morrill, J., Kulcinskaja, E., Sulewska, A.M., Lahtinen, S., Stålbrand, H., Svensson, B. and Hachem, M.A. (2015) The GH5 1,4- $\beta$-Mannanase from Bifidobacteriumanima- 
lis subsp. lacti s Bl-04 Possesses a Low-Affinity Mannan-Binding Module and Highlights the Diversity of Mannanolytic Enzymes. BMC Biochemistry, 16, 26. https://doi.org/10.1186/s12858-015-0055-4

[41] Bhattacharya, S., Ploplis, V.A. and Castellino, F.J. (2012) Bacterial Plasminogen Receptors Utilize Host Plasminogen System for Effective Invasion and Dissemination. Journal of Biomedicine and Biotechnology, 2012, Article ID: 482096. https://doi.org/10.1155/2012/482096

[42] Sanderson-Smith, M.L., De Oliveira, D.M., Ranson, M. and McArthur, J.D. (2012) Bacterial Plasminogen Receptors: Mediators of a Multifaceted Relationship. Journal of Biomedicine and Biotechnology, 2012, Article ID: 272148. https://doi.org/10.1155/2012/272148

[43] Salazar, N., Castiblanco-Valencia, M.M., da Silva, L., de Castro, Í., Monaris, D., Masuda, H.P., Barbosa, A.S. and MattosArêas, A.P. (2014) Staphylococcus aureus Manganese Transport Protein C (MntC) Is an Extracellular Matrix- and Plasminogen-Binding Protein. PLoS ONE, 9, e112730. https://doi.org/10.1371/journal.pone.0112730

[44] Candela, M. (2010) DnaK from Bifidobacteriumanimalis subsp. lactis Is a Surface-Exposed Human Plasminogen Receptor Upregulated in Response to Bile Salts. Microbiology, 156, 1609-1618. https://doi.org/10.1099/mic.0.038307-0

[45] Westermann, C., Gleinser, M., Corr, S.C. and Riedel, C.U. (2016) A Critical Evaluation of Bifidobacterial Adhesion to the Host Tissue. Frontiers in Microbiology, 7, 1220. https://doi.org/10.3389/fmicb.2016.01220

[46] Castaldo, C., Vastano, V., Siciliano, R.A., Candela, M., Vici, M., Muscariello, L., Marasco, R. and Sacco, M. (2009) Surface Displaced Alfa-Enolase of Lactobacillus plantarum Is a Fibronectin Binding Protein. Microbial Cell Factories, 8, 14. https://doi.org/10.1186/1475-2859-8-14

[47] Das, M.R. (2016) Molecular Association of Glucose-6-Phosphate Isomerase and Pyruvate Kinase M2 with Glyceraldehyde-3-Phosphate Dehydrogenase in Cancer Cells. BMC Cancer, 16, 152. https://doi.org/10.1186/s12885-016-2172-x

[48] Aziz, M. (2016) Biomimicry as an Approach for Bio-Inspired Structure with the Aid of Computation. Alexandria Engineering Journal, 55, 707-714. https://doi.org/10.1016/j.aej.2015.10.015

[49] Bhushan, B. (2009) Biomimetics: Lessons from Nature-An Overview. Philosophical Transactions of the Royal Society: A Mathematical Physical and Engineering Sciences, 367, 1445-1486. https://doi.org/10.1098/rsta.2009.0011

[50] McCarty, M. (2009) Life of Bionics Founder a Fine Adventure. Dayton Daily News.

[51] Vincent, J.F., Bogatyreva, O.A., Bogatyrev, N.R., Bowyer, A. and Pahl, A.K. (2006) Biomimetics: Its Practice and Theory. Journal of the Royal Society Interface, 3, 471-482. https://doi.org/10.1098/rsif.2006.0127

[52] Shimomura, M. (2012) Engineering Biomimetics: Integration of Biology and Nanotechnology. In: Design for Innovative Value towards a Sustainable Society, Springer, Dordrecht, 905-907. https://doi.org/10.1007/978-94-007-3010-6_186

[53] Hwang, J., Jeong, Y., Park, J.M., Lee, K.H., Hong, J.W. and Choi, J. (2015) Biomimetics: Forecasting the Future of Science, Engineering, and Medicine. International Journal of Nanomedicine, 10, 5701.

[54] Romei, F. (2008) Leonardo Da Vinci. The Oliver Press, Minneapolis.

[55] Sanchez, C., Arribart, H. and Guille, M.M. (2005) Biomimetism and Bioinspiration as Tools for the Design of Innovative Materials and Systems. Nature Materials, 4, 
277-288. https://doi.org/10.1038/nmat1339

[56] Vincent, J.F.V. (2009) Biomimetics-A Review. Proceedings of the Institution of Mechanical Engineers, Part H: Journal of Engineering in Medicine, 223, 919-939. https://doi.org/10.1243/09544119JEIM561

[57] Sleytr, U.B., Schuster, B., Egelseer, E.M. and Pum, D. (2014) S-Layers: Principles and Applications. FEMS Microbiology Reviews, 38, 823-864. https://doi.org/10.1111/1574-6976.12063

[58] Ucisik, M.H., Sleytr, U.B. and Schuster, B. (2015) Emulsomes Meet S-Layer Proteins: An Emerging Targeted Drug Delivery System. Current Pharmaceutical Biotechnology, 16, 392-405. https://doi.org/10.2174/138920101604150218112656

[59] Watson, H. (2015) Biological Membranes. Essays in Biochemistry, 59, 43-69. https://doi.org/10.1042/bse0590043

[60] Von Heijne, G. (2006) Membrane-Protein Topology. Nature Reviews Molecular Cell Biology, 7, 909-918. https://doi.org/10.1038/nrm2063

[61] Giess, F., Friedrich, M.G., Heberle, J., Naumann, R.L. and Knoll, W. (2004) The Protein-Tethered Lipid Bilayer: A Novel Mimic of the Biological Membrane. Biophysical Journal, 87, 3213-3220. https://doi.org/10.1529/biophysj.104.046169

[62] Schuster, B., Pum, D. and Sleytr, U.B. (2008) S-Layer Stabilized Lipid Membranes. Biointerphases, 3, FA3-FA11. https://doi.org/10.1116/1.2889067

[63] Schuster, B., et al. (2004) S-Layer Proteins as Supporting Scaffoldings for Functional Lipid Membranes. IEEE Transactions on Nanobioscience, 3, 16-21. https://doi.org/10.1109/TNB.2004.824267

[64] Rodrigues-Oliveira, T., et al. (2017) Archaeal S-Layers: Overview and Current State of the Art. Frontiers in Microbiology, 8, 2597.

https://doi.org/10.3389/fmicb.2017.02597

[65] Albers, S.-V. and Meyer, B.H. (2011) The Archaeal Cell Envelope. Nature Reviews Microbiology, 9, 414-426. https://doi.org/10.1038/nrmicro2576

[66] Ford, M.J., Nomellini, J.F. and Smit, J. (2007) S-Layer Anchoring and Localization of an S-Layer-Associated Protease in Caulobacter crescentus. Journal of Bacteriology, 189, 2226-2237. https://doi.org/10.1128/JB.01690-06

[67] Weygand, M., Wetzer, B., Pum, D., Sleytr, U.B., Cuvillier, N., Kjaer, K., Howes, P.B. and Lösche, M. (1999) Bacterial S-Layer Protein Coupling to Lipids: X-Ray Reflectivity and Grazing Incidence Diffraction Studies. Biophysical Journal, 76, 458-468. https://doi.org/10.1016/S0006-3495(99)77213-9

[68] Lagny, T.J. and Bassereau, P. (2015) Bioinspired Membrane-Based Systems for a Physical Approach of Cell Organization and Dynamics: Usefulness and Limitations. Interface Focus, 5, Article ID: 20150038. https://doi.org/10.1098/rsfs.2015.0038

[69] Khan, M.S., Dosoky, N.S. and Williams, J.D. (2013) Engineering Lipid Bilayer Membranes for Protein Studies. International Journal of Molecular Sciences, 14, 21561-21597. https://doi.org/10.3390/ijms141121561

[70] Kunitake, T. (1992) Synthetic Bilayer Membranes: Molecular Design, Self-Organization, and Application. Angewandte Chemie International Edition, 31, 709-726. https://doi.org/10.1002/anie.199207091

[71] Hirano-Iwata, A., et al. (2009) Free-Standing Lipid Bilayers in Silicon ChipsMembrane Stabilization Based on Microfabricated Apertures with a Nanometer-Scale Smoothness. Langmuir, 26, 1949-1952. https://doi.org/10.1021/la902522j

[72] Ricker, J.V., Tsvetkova, N.M., Wolkers, W.F., Leidy, C., Tablin, F., Longo, M. and 
Crowe, J.H. (2003) Trehalose Maintains Phase Separation in an Air-Dried Binary Lipid Mixture. Biophysical Journal, 84, 3045-3051. https://doi.org/10.1016/S0006-3495(03)70030-7

[73] Schuster, B. and Sleytr, U.B. (2009) Composite S-Layer Lipid Structures. Journal of Structural Biology, 168, 207-216. https://doi.org/10.1016/j.jsb.2009.03.004

[74] Knoll, W., Naumann, R., Friedrich, M., Robertson, J.W.F., Lösche, M., Heinrich, F., McGillivray, D.J., et al. (2008) Solid Supported Lipid Membranes: New Concepts for the Biomimetic Functionalization of Solid Surfaces. Biointerphases, 3, FA125-FA135. https://doi.org/10.1116/1.2913612

[75] Lei, G. and MacDonald, R.C. (2003) Lipid Bilayer Vesicle Fusion: Intermediates Captured by High-Speed Microfluorescence Spectroscopy. Biophysical Journal, 85, 1585-1599. https://doi.org/10.1016/S0006-3495(03)74590-1

[76] Monteiro, N., Martins, A., Reis, R.L. and Neves, N.M. (2014) Liposomes in Tissue Engineering and Regenerative Medicine. Journal of the Royal Society Interface, 11, Article ID: 20140459. https://doi.org/10.1098/rsif.2014.0459

[77] Ucisik, M.H., Küpcü, S., Debreczeny, M., Schuster, B. and Sleytr, U.B. (2013) S-Layer Coated Emulsomes as Potential Nanocarriers. Small, 9, 2895-2904. https://doi.org/10.1002/smll.201203116

[78] Lombardo, D., et al. (2016) Soft Interaction in Liposome Nanocarriers for Therapeutic Drug Delivery. Nanomaterials, 6, 125. https://doi.org/10.3390/nano6070125

[79] Hynönen, U. and Palva, A. (2013) Lactobacillus Surface Layer Proteins: Structure, Function and Applications. Applied Microbiology and Biotechnology, 97, 5225-5243. https://doi.org/10.1007/s00253-013-4962-2

[80] Ma, Y., Goyette, J., Poole, K. and Gaus, K. (2017) Introducing Membrane Charge and Membrane Potential to T Cell Signalling. Frontiers in Immunology, 8, 1513. https://doi.org/10.3389/fimmu.2017.01513

[81] Hollmann, A., Delfederico, L., Glikmann, G., De Antoni, G., Semorile, L. and Disalvo, E.A. (2007) Characterization of Liposomes Coated with S-Layer Proteins from Lactobacilli. Biochimica et BiophysicaActa (BBA) Biomembranes, 1768, 393-400. https://doi.org/10.1016/j.bbamem.2006.09.009

[82] Pouwels, P.H., Leer, R.J., Shaw, M., den Bak-Glashouwer, M.-J.H., Tielen, F.D., Smit, E., Martinez, B., Jore, J. and Conway, P.L. (1998) Lactic Acid Bacteria as Antigen Delivery Vehicles for Oral Immunization Purposes. International Journal of Food Microbiology, 41, 155-167. https://doi.org/10.1016/S0168-1605(98)00048-8

[83] Sleytr, U.B., Huber, C., Ilk, N., Pum, D., Schuster, B. and Egelseer, E.M. (2007) S-Layers as a Tool Kit for Nanobiotechnological Applications. FEMS Microbiology Letters, 267, 131-144. https://doi.org/10.1111/j.1574-6968.2006.00573.x

[84] Mader, C., Küpcü, S., Sleytr, U.B. and Sára, M. (2000) S-Layer-Coated Liposomes as a Versatile System for Entrapping and Binding Target Molecules. Biochimica et BiophysicaActa (BBA) Biomembranes, 1463, 142-150. https://doi.org/10.1016/S0005-2736(99)00190-X

[85] Del Rosario, R.B., Baron, L.A., Lawton, R.G. and Wahl, R.L. (1992) Streptavidin-Biotinylated IgG Conjugates: A Simple Procedure for Reducing Polymer Formation. International Journal of Radiation Applications and Instrumentation. Part B. Nuclear Medicine and Biology, 19, 417-421. https://doi.org/10.1016/0883-2897(92)90128-L

[86] Guo, X., Wu, Z. and Guo, Z. (2012) New Method for Site-Specific Modification of Liposomes with Proteins Using Sortase A-Mediated Transpeptidation. Bioconjugate 
Chemistry, 23, 650-655. https://doi.org/10.1021/bc200694t https://pubs.acs.org/doi/abs/10.1021/bc200694t

[87] Bozzuto, G. and Molinari, A. (2015) Liposomes as Nanomedical Devices. International Journal of Nanomedicine, 10, 975. https://doi.org/10.2147/IJN.S68861

[88] Gill, B., Singh, J., Sharma, V. and Kumar, S.H. (2012) Emulsomes: An Emerging Vesicular Drug Delivery System. Asian Journal of Pharmaceutics, 6, 87. https://doi.org/10.4103/0973-8398.102930

[89] Major, M., Prieur, E., Tocanne, J.F., Betbeder, D. and Sautereau, A.M. (1997) Characterisation and Phase Behaviour of Phospholipid Bilayers Adsorbed on Spherical Polysaccharidic Nanoparticles. Biochimica et BiophysicaActa (BBA) Biomembranes, 1327, 32-40. https://doi.org/10.1016/S0005-2736(97)00041-2

[90] Goñi, F.M. (2014) The Basic Structure and Dynamics of Cell Membranes: An Update of the Singer-Nicolson Model. Biochimica et BiophysicaActa (BBA) Biomembranes, 1838, 1467-1476. https://doi.org/10.1016/j.bbamem.2014.01.006

[91] Ziani, K., Fang, Y. and McClements, D.J. (2012) Encapsulation of Functional Lipophilic Components in Surfactant-Based Colloidal Delivery Systems: Vitamin E, Vitamin D, and Lemon Oil. Food Chemistry, 134, 1106-1112.

https://doi.org/10.1016/j.foodchem.2012.03.027

[92] Lin, C.H., Chen, C.H., Lin, Z.C. and Fang, J.Y. (2017) Recent Advances in Oral Delivery of Drugs and Bioactive Natural Products Using Solid Lipid Nanoparticles as the Carriers. Journal of Food and Drug Analysis, 25, 219-234. https://doi.org/10.1016/j.jfda.2017.02.001

[93] Ucisik, M.H., Küpcü, S., Schuster, B. and Sleytr, U.B. (2013) Characterization of Curcuemulsomes: Nanoformulation for Enhanced Solubility and Delivery of Curcumin. Journal of Nanobiotechnology, 11, 37. https://doi.org/10.1186/1477-3155-11-37

[94] Walsh, T.J., Finberg, R.W., Arndt, C., Hiemenz, J., Schwartz, C., Bodensteiner, D., Pappas, P., et al. (1999) Liposomal Amphotericin B for Empirical Therapy in Patients with Persistent Fever and Neutropenia. New England Journal of Medicine, 340, 764-771. https://doi.org/10.1056/NEJM199903113401004

[95] Vyas, S.P., Subhedar, R. and Jain, S. (2006) Development and Characterization of Emulsomes for Sustained and Targeted Delivery of an Antiviral Agent to Liver. Journal of Pharmacy and Pharmacology, 58, 321-326. https://doi.org/10.1211/jpp.58.3.0005

[96] Khan, Z.A., Tripathi, R. and Mishra, B. (2012) Methotrexate: A Detailed Review on Drug Delivery and Clinical Aspects. Expert Opinion on Drug Delivery, 9, 151-169. https://doi.org/10.1517/17425247.2012.642362

[97] Liou, J.W., Hung, Y.J., Yang, C.H. and Chen, Y.C. (2015) The Antimicrobial Activity of Gramicidin A Is Associated with Hydroxyl Radical Formation. PLoS ONE, 10, e0117065. https://doi.org/10.1371/journal.pone.0117065

[98] Hladky, S.B., Leung, J.C. and Fitzgerald, W.J. (1995) The Mechanism of Ion Conduction by Valinomycin: Analysis of Charge Pulse Responses. Biophysical Journal, 69, 1758-1772. https://doi.org/10.1016/S0006-3495(95)80046-9

[99] Volinsky, R., Kolusheva, S., Berman, A. and Jelinek, R. (2006) Investigations of Antimicrobial Peptides in Planar Film Systems. Biochimica et BiophysicaActa (BBA) Biomembranes, 1758, 1393-1407. https://doi.org/10.1016/j.bbamem.2006.03.002

[100] Bechinger, B. (1997) Structure and Functions of Channel-Forming Peptides: Magainins, Cecropins, Melittin and Alamethicin. The Journal of Membrane Biology, 
156, 197-211. https://doi.org/10.1007/s002329900201

[101] Sankararamakrishnan, R., Adcock, C. and Sansom, M.S. (1996) The Pore Domain of the Nicotinic Acetylcholine Receptor: Molecular Modeling, Pore Dimensions, and Electrostatics. Biophysical Journal, 71, 1659-1671.

https://doi.org/10.1016/S0006-3495(96)79370-0

[102] Reddish, F.N., Miller, C.L., Gorkhali, R. and Yang, J.J. (2017) Calcium Dynamics Mediated by the Endoplasmic/Sarcoplasmic Reticulum and Related Diseases. International Journal of Molecular Sciences, 18, 1024.

https://doi.org/10.3390/ijms18051024

\section{Abbreviations}

aHL- $\alpha$ : Haemolysin

AMP: Anti-Microbial Peptide

AZT: Azidothymidine

BLM: Bilayer membrane

CD-14: Complementary deteming factor -14

Ef-Tu: Elongation factor-Tu

EGFP: Enhanced Green fluorescent protein

GAPDH: Glyceraldehyde 3-phosphate dehydrogenase

GPI: Glucose Phosphatase isomerase

GRAS: Generally Regarded As Safe

HSP: Heat shock Protein

HepG2: Human Liver Carcinoma Cells

IL-8: Interleukin -8

LAB: Lactic Acid Bacteria

MTX: Methotrexate

nAchR: Nicotinic Acetylcholine Receptor

RyR1: Ryanodine receptor

SLP: Surface layer protein

SsLM: S-layer stabilized lipid membrane

tPA: Tissue Plasminogen Activator

VDAC: Voltage Dependent Anion Channel 